\title{
THE IFC-BRIDGE PROJECT - EXTENDING THE IFC STANDARD TO ENABLE HIGH-QUALITY EXCHANGE OF BRIDGE INFORMATION MODELS
}

\author{
André Borrmann ${ }^{1}$, Sergej Muhič ${ }^{2}$, Juha Hyvärinen ${ }^{3}$, Tim Chipman ${ }^{4}$, Stefan Jaud ${ }^{1}$, \\ Christophe Castaing ${ }^{5}$, Claude Dumoulin ${ }^{6}$, Thomas Liebich ${ }^{2}$, Laura Mol ${ }^{7}$ \\ ${ }^{1}$ Technical University of Munich, Germany, ${ }^{2}$ AEC3 Deutschland GmbH, Germany \\ ${ }^{3}$ VTT, Finland, ${ }^{4}$ Constructivity LLC, USA, ${ }^{5}$ EGIS, France \\ ${ }^{6} \mathrm{MiND}$ project, France, ${ }^{7}$ Gobar Consulting Group, The Netherlands
}

\begin{abstract}
The paper reports on the buildingSMART International project IFC-Bridge that developed an extension of the vendor-neutral data exchange standard Industry Foundation Classes (IFC). The paper highlights the importance of a well-defined development process and the involvement of an international expert panel. It also discusses the need to focus on "low hanging fruits" by considering only the most widespread bridge types and implementing the data exchange scenarios that provide the most benefit. The paper describes both the development process and the outcome - the actual extension of the IFC standard. In this regard, emphasis is given to the general principles of extending IFC, such as minimizing the number of new entities.
\end{abstract}

\section{Introduction}

Industry Foundation Classes (IFC) is a comprehensive data model allowing the detailed geometric and semantic description of buildings and is widely used as a software vendor-independent BIM data exchange standard. It is developed by the international non-profit organization buildingSMART and has been accepted as an ISO standard in 2013. Up to version IFC4, the IFC standard was mainly focused on buildings. However, due to increasing international demand, a substantial extension of the standard to support infrastructure facilities is being carried out.

To this end, the so-called Infra Room, a subdivision of buildingSMART International (bSI) with its own steering committee, was founded in 2013. It developed a roadmap and started a number of projects to develop the necessary extensions. The first project was IfcAlignment which defined extensions for describing the alignment of linear infrastructure assets (Liebich et al. 2017). On this basis, the IFC Infra Overall Architecture project was conducted in order to specify general principles to be followed by all Infrastructure extension projects. On top of that, the projects IfcBridge, IfcRail, IfcRoad and IfcTunnel have or will be initiated.

In this paper, we report on the IfcBridge project; its devel-

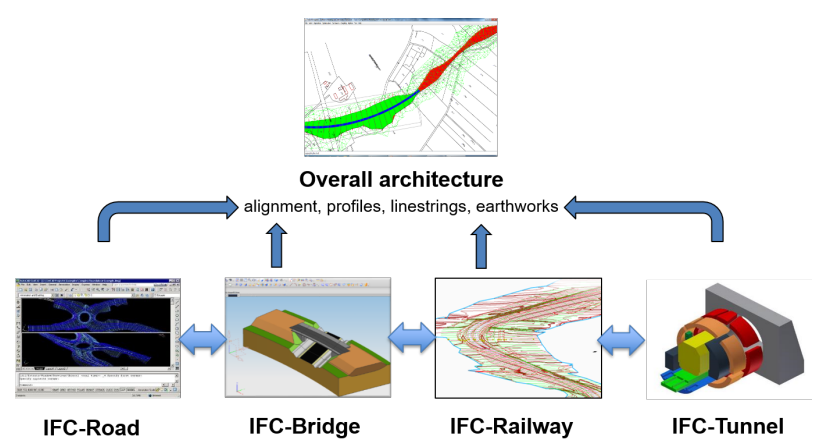

Figure 1: Overview on the IFC-Infra extensions.

opment process and the results.

\section{The extension project}

In response to the urgent demand of international infrastructure stakeholders for extending IFC for bridges, the standard development project was initiated by Infra Room as a fast-track project with a duration of 2 years. It started in January 2017 and was completed with a slight delay in April 2019. Due to the limited time and resources available, it was essential that the project focused on "low hanging" fruits; i.e. selecting use cases to be supported that bring the most value to the future users of the standard. The IfcBridge extension project followed the formal project execution guidelines of bSI that came into effect in 2015 (buildingSMART International 2015). They define two essential components to be implemented by each project:

- the organizational structure,

- the development process.

The following section will report in detail on each of the phases.

\section{The organizational structure}

For each project, a project team has to be formed. It must consist of a group of international experts, preferably a combination of domain experts and IFC specialists. In 


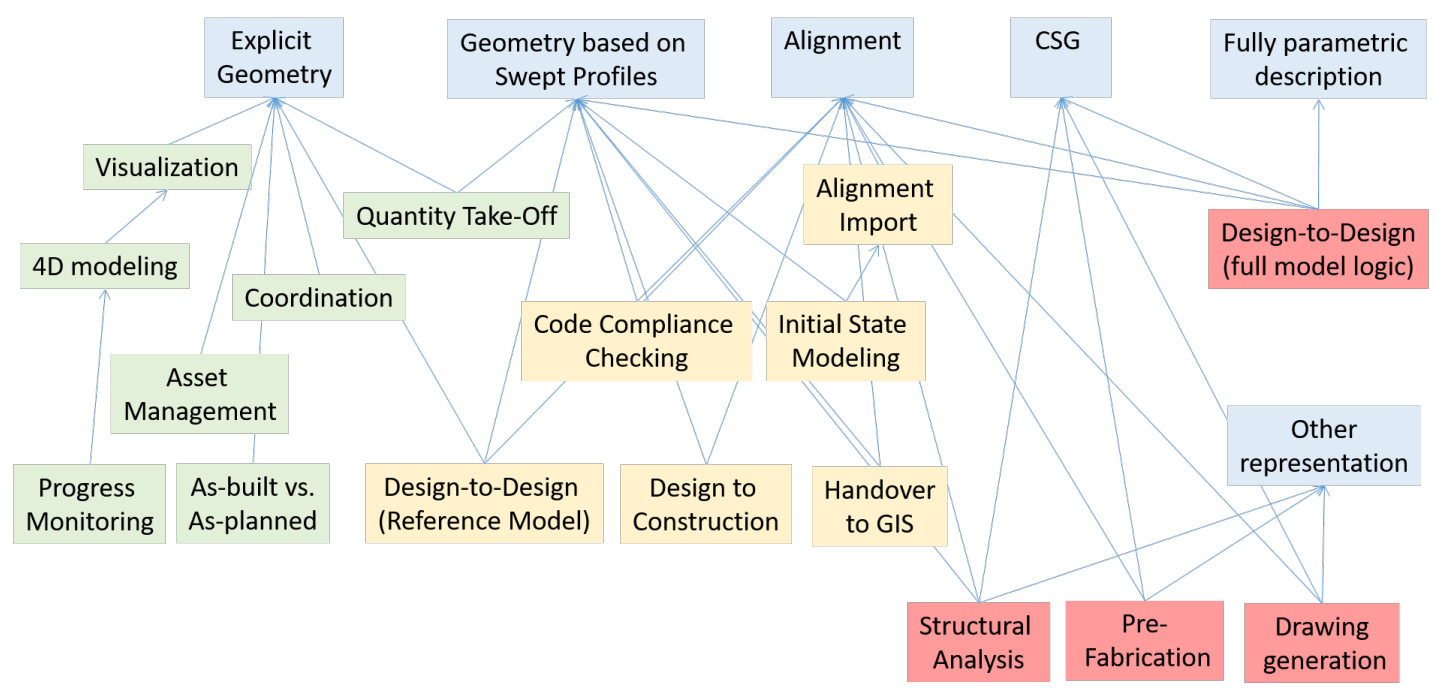

Figure 2: Dependence of the use cases on specific geometry representations.

the case of the IfcBridge project, the project team was composed of members from Finland, Germany, France, USA and China. The project team is led by the project lead and the technical lead.

The project team met on a bi-weekly basis and reported to the Infra Room Project Steering Committee (IRPSC) on a monthly basis, which monitors project progress and funds. In addition, an international expert panel must be formed comprising experts from the domain (here: bridge engineers, contractors and operators). Expert panel meetings were hold in regular intervals in order to find the scope of the project, discuss the use cases and present the final results.

\section{The development process}

As demanded by bSI guidelines, the IfcBridge project implemented the following development phases:

1. Requirements Analysis

2. Taxonomy Analysis

3. Conceptual model development

4. IFC schema extension proposal (draft)

5. Validation

6. IFC schema extension proposal (final)

7. Formal acceptance

\section{Requirements Analysis}

An important lesson learned from more than 25 years of developing the open data standard IFC (Laakso \& Kiviniemi 2012) is that it is of utmost importance to first define the scope and use cases to be covered by an extension project. This becomes even more obvious when considering (1) the large extent of the existing data model (the latest release IFC4.1 comprises 801 entities), (2) the limited time and resources available for the developing the extensions, and (3) the goal of lowering the effort for software implementation to enable a fast uptake of the standard.

The requirements analysis performed by the project team in close collaboration with the international expert panel resulted in the defining the scope as detailed in the following sub-sections (Castaing et al. 2018).

\section{Bridge types covered}

Based on discussion with the expert panel and an analysis of the most widespread bridges constructed worldwide, the following bridge types were considered in the IfcBridge project:

- Slab bridge

- Girder bridge,

- Slab-girder bridge

- Box-girder bridge

- Frame bridge

- Rigid frame bridge

- Culvert

Bridges of the following types were not directly considered, but were expected to be representable by the extension:

- Truss bridge

- Arch bridge

- Cantilever bridge

- Cable-stayed bridge

- Suspension bridge

From a material viewpoint, the following bridge types were 


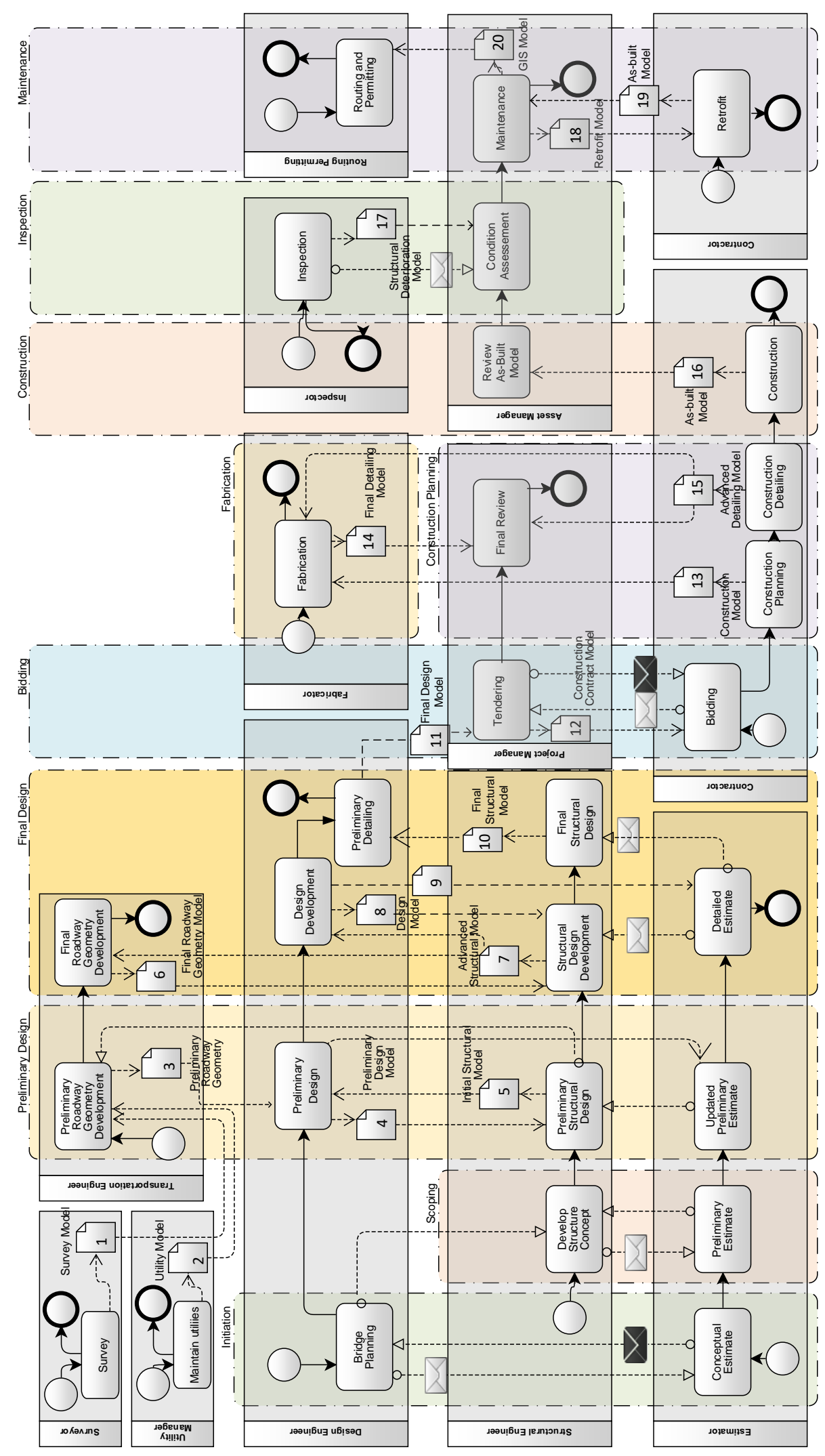

Figure 3: Process map developed by the IFC-Bridge project, based on prior work by the US FHWA BrIM project. 
decided to be covered:

- Reinforced concrete bridges

- Prestressed concrete bridges

- Steel/Concrete composite bridges

- Steel girder bridges

- Steel bridges

\section{Use cases covered}

The project team performed an in-depth analysis of the use cases for a software vendor-independent bridge data exchange format in order to identify those that are supposed to be supported by the extension, and those that are considered out-of-scope. The analysis included specifying the sending and the receiving application, rough descriptions of the required geometry representations and the semantic data as well as an assessment of the complexity of the realization of the required data structure. In addition, the priority of individual use case support was identified through intense consulting of the expert panel.

Based on a careful analysis of the benefits of the individual use cases and the complexity and effort involved with defining the necessary data structures, the project team decided to prioritize the following use cases for explicit consideration when designing the IFC-Bridge extension:

- Initial State Modeling

- Import of major road / railway parameters

- Technical Visualization

- Coordination / Collison Detection

- 4D Construction Sequence Modeling

- Quantity Take-Off

- Progress Monitoring

- As-built vs. as-planned comparison

- Handover to asset management

- Handover to GIS for spatial analysis

- Design to design (reference model)

Due to overly high complexity, the following use cases were marked as out of scope of the fast-track project:

- Design to Design (Full model logic)

- Structural analysis

- Code Compliance Checking

- Drawing generation and exchange

- Prefabrication and manufacturing

The full design-to-design use case, which incorporates the model's design logic (Ji et al. 2013), was excluded as it would require a major effort from both bSI in defining the necessary data structures and from software vendors in correctly implementing them. It was emphasized that the exclusion from the fast-track project does not mean that these use cases will not be addressed by future IFC-Bridge extensions.

\section{Geometry}

The analysis revealed that the in-scope use cases require explicit BRep geometry and/or implicit geometry based on sweeps (Figure 2).

More specifically, many of the supported use cases demand the usage of sweeps for representing the superstructure elements (deck, shoulder, etc.), rebar and the pre-stressing elements. It was well agreed by the project team that the usage of triangulated face sets is not appropriate for these elements in many use cases, due to the loss in accuracy and the excessive increase in data size. The use of sweeps is a strong demand for realizing meaningful data exchanges.

The entity IfcSectionedSolidHorizontal plays an important role. It has been introduced with IFC 4.1 as a result of the development activities in the IFC-Alignment and the IFC Infra Overall Architecture projects (Liebich et al. 2017)(Borrmann et al. 2017). The entity allows to perform sweeps along an alignment where the cross-section's yvector is kept pointing in the global z direction, in contrary to the conventional IfcSweptAreaSolid where the crosssection is kept perpendicular to the sweeping path at any time. IfcSectionedSolidHorizontal has been introduced for correctly modeling elements of infrastructure facilities (roadway layers, bridge decks) and will be applied in this sense in the IFC-Bridge extensions. It will be included in the Bridge Model View Definitions (see below).

In practice, both IfcSweptAreaSolid and IfcSectionedSolidHorizontal are needed to define alignment-based geometry, depending on how the element is built. Having in mind that the global $\mathrm{z}$ direction can be easily identified on site, it is commonly used for cast-in-place processes. By contrast, if the element is pre-cast in a plant in a horizontal formwork, it is required to use a profile perpendicular to the sweeping path.

\section{Process Map}

The process map depicted in Figure 3 has been developed according to the BPMN standard to clearly identify the exchange requirements and associate them with dedicated data exchange scenarios. Its purpose is to provide a general reference workflow, i.e. deviations in national or regional processes are possible.

\section{Taxonomy Analysis}

In the following phase, the bridge taxonomy was analyzed. The goal was to identify concepts specific to bridge construction and to find commonly used English terms for them. To this end, the following sources were analyzed:

- French MiND project documentation

- FHWA

- Korean IfcRoad proposal 


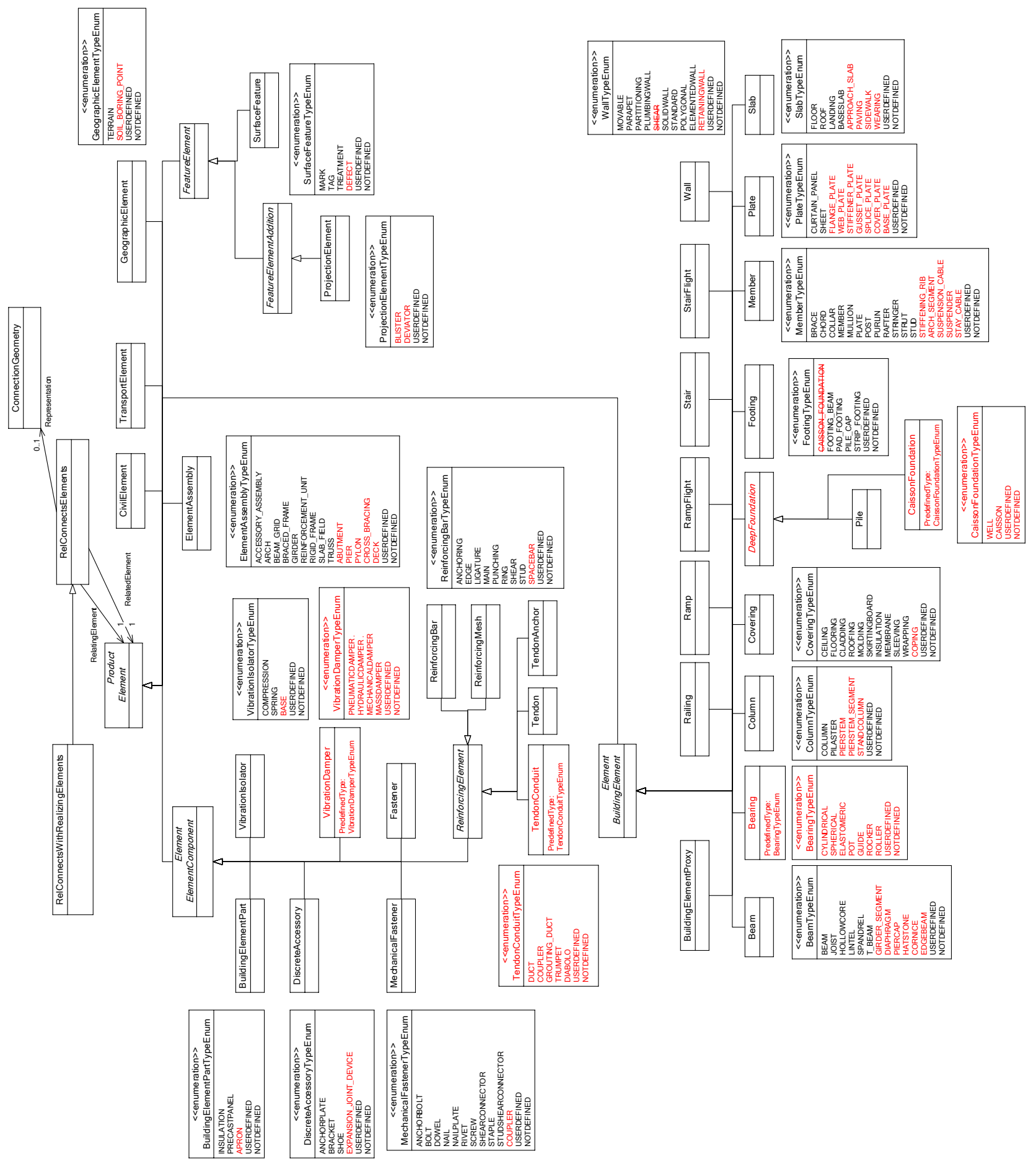

Figure 4: The main part of the conceptual model of the IFC-Bridge extensions. New elements are marked in red.

- Chinese IfcRail proposal

- German road standard OKSTRA

- UniClass 2015

- OmniClass
In addition, the published results from various research projects were taken into account (Ji et al. 2013, Sacks et al. 2018, Hüthwohl et al. 2018).

The information from the sources was subsequently merged and harmonized, first by using spreadsheets shared 
among the project team, later by using the web-based tool BIMQ by AEC3 Germany.

\section{Conceptual model development}

In the next step, the conceptual model was developed. The conceptual model describes the IFC extensions mostly by using UML diagrams in combination with documentation text. As opposed to the approach taken by OGC, the bSI conceptual model takes the particularities of the existing IFC data model into account and describes, for example, new sub-classes as refinements to existing IFC classes. It also defines attributes and properties where appropriate. The major part of the conceptual model is depicted in UML in Figure 4.

It is very important to note that the IfcBridge project implemented the guidelines of the Infra Overall Architecture Project (Borrmann et al. 2017), which demand to keep the number of new entities to minimum and instead provide a maximum of re-usage of existing classes. A good example is the Wing Wall of an Abutment. It is not necessary to define a new class for it, instead the existing IfcWall can be used. However, it may be appropriate to extend the enumeration of the predefined types of an entity. Where necessary, the documentation was modified to include bridge concepts.

Due to the principle described above, the resulting conceptual model only adds a minimum amount of new entities. At the same time however, a large number of new predefined types for a variety of entities were introduced. Figure 5 shows these extensions.

\section{Spatial elements}

In the IFC model, spatial structure elements are applied to capture the spatial hierarchy of a project. As the prior IFC data model was limited to buildings, a significant extension was necessary. A general concept applicable also for other types of facilities was implemented by means of the entities IfcFacility and IfcFacilityPart.

The new spatial entities defined are:

- IfcFacility - subtype of IfcSpatialStructureElement

- IfcFacilityPart - subtype of IfcSpatialStructureElement

- IfcBridge - subtype of IfcFacility

- IfcBridgePart - subtype of IfcFacilityPart

Figure 6 illustrates the extensions by means of an UML model.

\section{Physical elements}

The majority of physical elements of bridges can be described by means of the existing entities. The following new entities were defined to describe bridge-specific phys-

\begin{tabular}{|c|c|c|}
\hline \begin{tabular}{|l} 
IfCBeam: \\
GIRDER_SEGMENT \\
$: \quad$ DIAPHRAGM \\
$: \quad$ PIERCAP \\
$: \quad$ HATSTONE \\
CORNICE \\
EDGEBEAM
\end{tabular} & 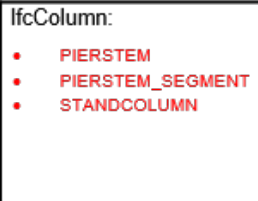 & $\begin{array}{l}\text { IfCCovering: } \\
\text { - } \quad \text { COPING }\end{array}$ \\
\hline $\begin{array}{ll}\text { IfCMember: } \\
\text { - } & \text { STIFFENING_RIB } \\
\text { - } & \text { ARCH_SEGMENT } \\
\text { : } & \text { SUSPENSION_CABLE } \\
\text { - } & \text { SUSPENDER } \\
\text { STAY_CABLE }\end{array}$ & \begin{tabular}{|ll} 
IfCPlate: \\
$:$ & FLANGE_PLATE \\
$:$ & WEB_PLATE \\
$:$ & STIFFENER_PLATE \\
$:$ & GUSSET_PLATE \\
$:$ & SPICE_PLATE \\
- & BASER_PLATE \\
& BASEATE
\end{tabular} & $\begin{array}{ll}\text { IfCSlab: } \\
\text { - } & \text { APPROACH_SLAB } \\
: & \text { PAVING } \\
\text { : } & \text { SIDEWALK } \\
& \text { WEARING }\end{array}$ \\
\hline $\begin{array}{l}\text { IfcWall: } \\
\text { - RETAININGWALL }\end{array}$ & \begin{tabular}{|ll} 
IfcElementAssembly: \\
: & ABUTMENT \\
: & PIER \\
: & PYLON \\
- & DECKS_BRACING
\end{tabular} & $\begin{array}{l}\text { IfcVibrationlsolator: } \\
\text { - BASE }\end{array}$ \\
\hline $\begin{array}{l}\text { IfcBuildingElementPart: } \\
\text { - APRON }\end{array}$ & $\begin{array}{l}\text { IfcDiscreteAccessory: } \\
\text { EXPANSION_JOINT_ } \\
\text { DEVICE }\end{array}$ & $\begin{array}{l}\text { IfCMechanicalFastener: } \\
\text { - COUPLER }\end{array}$ \\
\hline $\begin{array}{l}\text { IfCReinforcingBar: } \\
\text { - SPACEBAR }\end{array}$ & $\begin{array}{l}\text { IfcSurfaceFeature: } \\
\text { DEFECT }\end{array}$ & $\begin{array}{l}\text { IfcProjectionElement: } \\
\text { - } \quad \text { BLISTER } \\
\text { - }\end{array}$ \\
\hline $\begin{array}{l}\text { IfcGeographicElement: } \\
\text { - } \quad \text { SOIL_BORING_POINT }\end{array}$ & $\begin{array}{ll}\text { IfCBuildingSystem: } \\
\text { - } & \text { REINFORCING } \\
\text { - } & \text { PRESTRESSING }\end{array}$ & \\
\hline
\end{tabular}

Figure 5: The newly defined predefined types for existing entities.

ical elements:

- IfcBearing - subtype of IfcBuildingElement

- IfcDeepFoundation - subtype of IfcBuildingElement

- IfcCaissonFoundation - subtype of IfcDeepFoundation

- IfcVibrationDamper - subtype of IfcVibrationDamper

- IfcTendonConduit - subtype of IfcReinforcingElement

Figure 4 depicts an overview of the data model related to physical elements including the extensions. In addition, new predefined types were proposed for existing entities. The full list is provided in Figure 5.

\section{Systems}

New predefined types were defined for the existing entity IfcBuildingSystem in order to support a more appropriate representation of reinforcement and the prestressing system:

- REINFORCING

- PRESTRESSING 


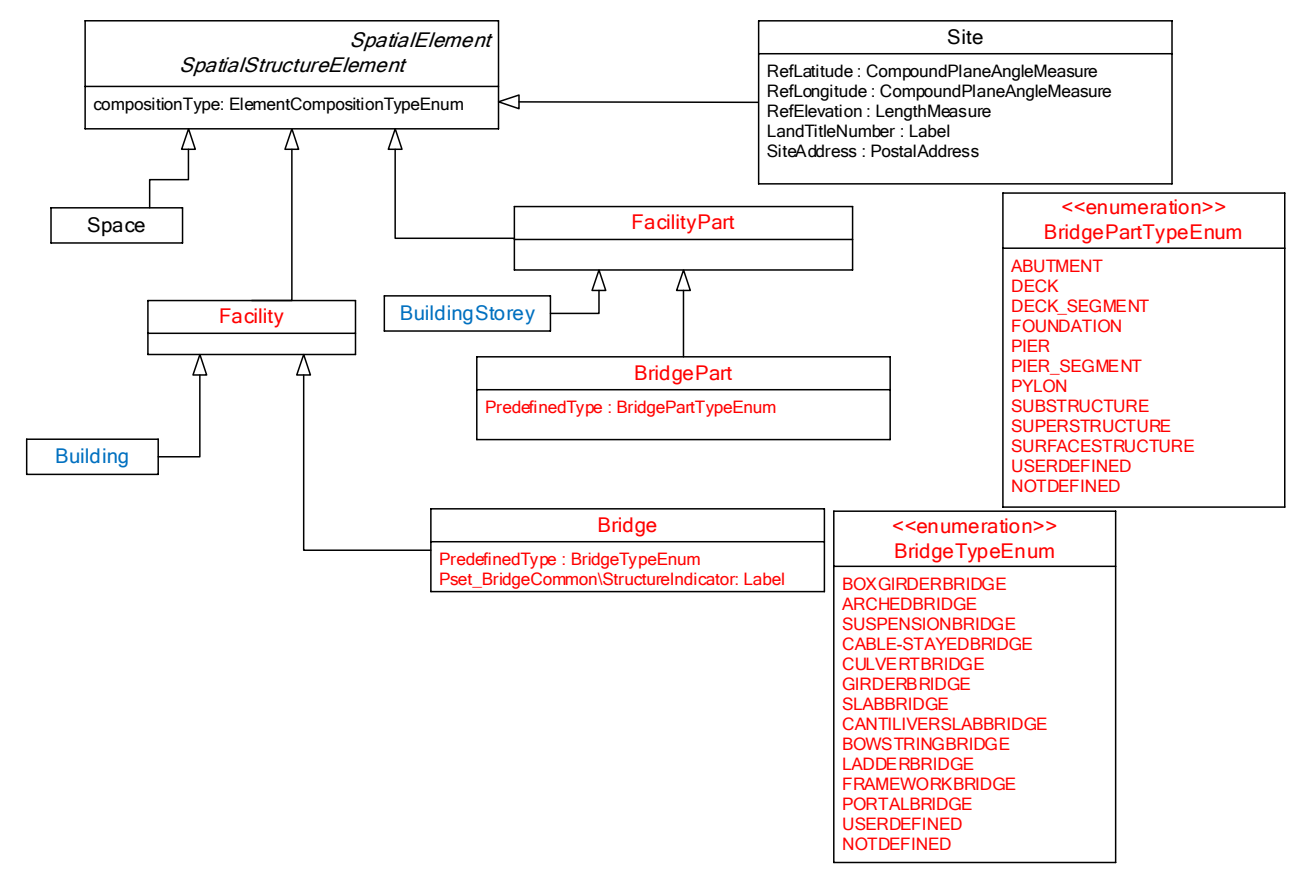

Figure 6: Extension of the spatial elements. New elements are marked in red.

\section{Positioning}

The new relationship IfcRelPositions (subtype of IfcRelConnects) may be used to relate IfcObjects for which placement or geometry is defined relative to alignments (or grids).

The presence of such relationship allows for modification scenarios where alignments may change and dependent objects may then have placement and geometry adjusted accordingly. Such relationship is similar in functionality as IfcRelConnectsPathElements, where the adjustment of a wall, beam, or column can then be propagated to connected walls, beams, or columns.

\section{Proposed IFC schema extension (draft)}

Based on the conceptual model, the actual extension of the IFC schema was realized. This was done by defining the corresponding EXPRESS schema. From the EXPRESS schema, all other data schemas supported by bSI are derived (ifcXML, ifcOWL). In addition, a comprehensive HTML documentation is generated. With respect to the latter, the project team created the documentation for new entities and updated those parts of the existing documentation where semantics were altered or extended.

The draft extension was published on bSI Forums for direct feedback from the international community.

\section{Validation}

To avoid ambiguities and identify deficiencies, the extension was validated through prototypical implementation in two IFC applications and several tests to confirm successful data exchange between these two applications. One of the employed applications is TUM Open Infra Platform (Amann et al. 2016), see Figure 8, the other one is eveBIM by CSTB.

\section{IFC Schema extension (final)}

For the publication of the final version of the schema extension, the bugs and ambiguities identified in the course of the validation phase were fixed. In addition, feedback from the international community was taken into account.

\section{Handling of properties}

Properties play an important role in IFC-based data exchange. They are not part of the schema but are be defined independently by means of the PropertySet mechanism (Borrmann et al. 2018). This allows for a dynamic extension of the schema and enables to fulfill the data exchange needs on a national, regional or authority level without requiring international consensus (Figure 9).

According to this principle, only a limited number of properties was defined as international properties forming part of the final specification. However, there are well-defined mechanisms for handling national or authority-specific 


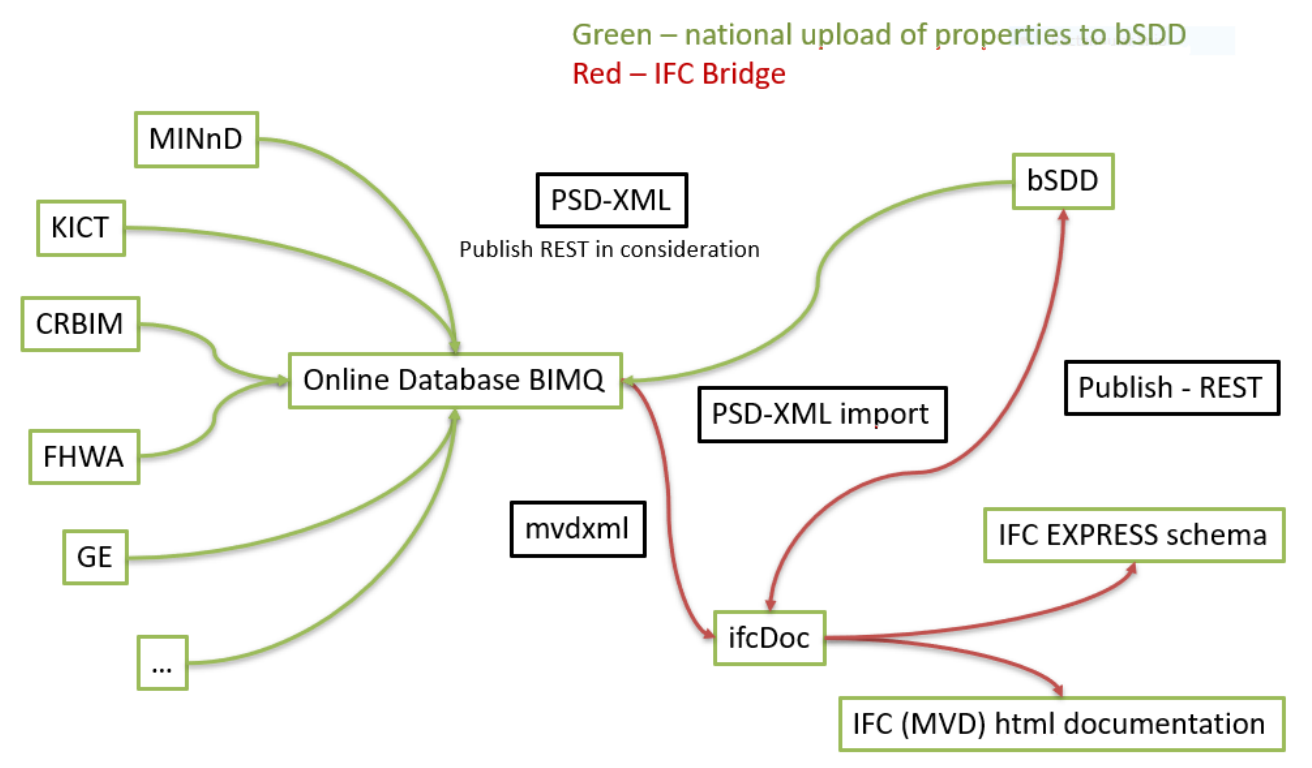

Figure 7: General approach taken by the IFC-Bridge project to defining and managing properties

properties, for example by means of the buildingSMART Data Dictionary (bsDD). Figure 7 illustrates the general approach taken by the IFC-Bridge project to defining and managing properties.

\section{Model View Definitions}

In order to reduce the complexity of the data model implementation, it was decided to map the use cases to the following basic Model View Definitions (MVDs).

- Bridge Reference View (Bridge RV)

- Alignment-based Bridge Reference View (Bridge ARV)

- Bridge Design Transfer View (Bridge DTV)

- Bridge Asset Management Handover View (Bridge AMV)

The decision was taken to align both the Bridge Reference View and the Bridge Design Transfer View with the existing views in IFC4, but extend them where necessary to capture the specifics of bridges.

The basic differentiation between RV and DTV is also applied to the Bridge MVDs. Most importantly, IfcCSGSolid (Constructive Solid Geometry Boolean Operations on Solids) is not supported by the Bridge RV, but by the Bridge DTV. Another important difference lies in the support of IfcFacetedBrep and IfcAdvancedBrep which are only realized in Bridge DTV. For representing BRep geometry in RV, the IfcPolygonalFaceSet representation must be used. Curved surfaces (NURBS) are not supported by RV. In addition, there will be the Alignment-based Reference View (Bridge ARV) which extends the IFC4 Reference
View by the support for IfcAlignment and IfcSectionedSolidHorizontal for positioning and geometry creation. The reason for introducing the additional MVD lies in the importance of alignment for linear infrastructure. As however, standard IFC viewers (which typically do not support alignment) should be able to visualize bridge models, the basic Bridge RV will not demand IfcAlignment to be supported, but rely instead on explicit geometry and on Cartesian coordinates for positioning. It is important to note that Bridge DTV does not have a non-alignment counterpart as it is expected that complex bridge geometric representations are always based on the alignment.

\section{Next steps}

The fast-track standardization project was finished in March 2019. It is followed by a deployment project where interested software vendors are invited to join a coordinated early implementation effort. In the frame of the project, the software vendors are receiving intensive support and gain the opportunity to provide direct feedback on the standard. If major deficiencies are detected in this process, the standard will be revised accordingly.

After successful completion, the official bSI standards adoption process is performed. Upon approval of the standards committee, the extension becomes the official IFC 4.2 candidate standard and is subsequently set for vote by the national or regional chapters of buildingSMART International. If accepted, the standard will become the official IFC 4.2 release.

If requested by the community, a further extension of the standard with additional bridge-specific elements can be 


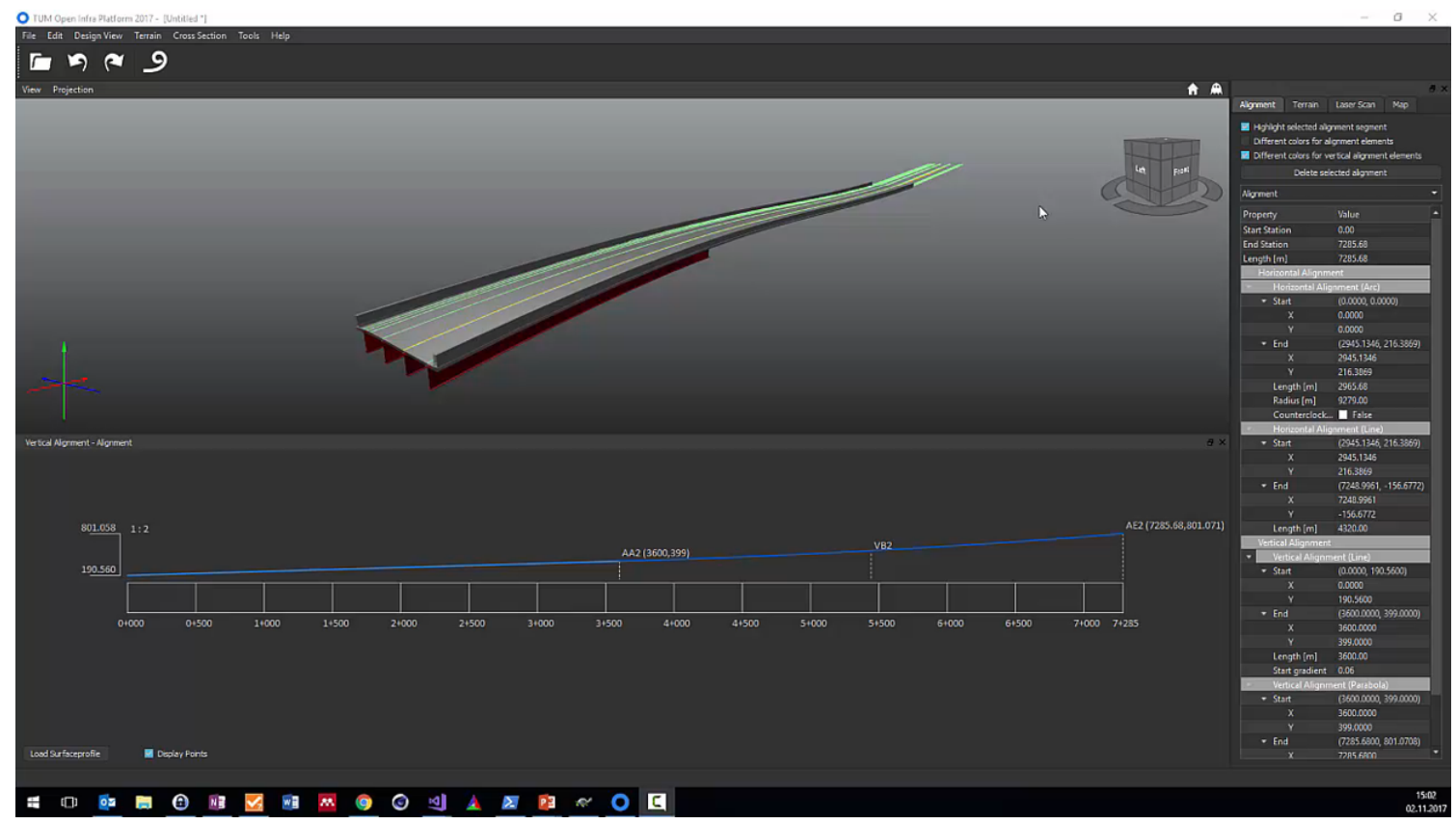

Figure 8: TUM Open Infra Platform visualizing bridge deck geometry created by alignment-based sweep

realized in a future IFC-Bridge 2.0 project. This may involve more advanced geometric representations to capture the parametrics of bridge design and enable their exchange between different design packages (Ji et al. 2013).

\section{Discussion}

The paper presented the extension of the vendor-neutral data format IFC developed in the course of the official buildingSMART International IFC Bridge project. The extension fulfilled a pressing request of the international BIM community to better support the data exchange of bridge information models.

The project showed that is possible to successfully develop an extension of significant extent in a limited time of only 2 years. However, a stringent process had to be implemented to reach this goal. The most important prerequisite for the success of the project was the clear definition of the bridge types to be included and the uses cases to be supported by the standardization effort. In this regard, it was essential to concentrate on the "low hanging fruits", i.e. on the most widespread bridge types and the most beneficial use cases with limited complexity.

The involvement of international expert panel through frequent online workshops proved to be a very helpful resource for critical reflection of the decisions taken by the project team.

For the actual extension, the guidelines laid down by the IFC-Infra Overall Architecture project were carefully followed. Most importantly, new entities were only defined where necessary, i.e. where existing entities did not provide the semantics required for bridge-specific concepts. In most cases, an extension of the predefined type enumerations was sufficient. This approach helps to keep the effort low for software vendors that already implemented previous versions of IFC when integrating the extensions. With respect to properties, only a limited number were defined and became part of the official international specification

A shortcoming of the current bSI process is the suboptimal support by software tools. Although the project team was able to use BIM-Q to collect taxonomy items and map them to IFC entities, the synchronization with the UML tool for creating the conceptual model remained a mainly manual task. At this point, inconsistencies may easily arise. Particular challenging was the application of IfcDoc for creating the final draft schema and its documentation. Again manual work was necessary to a large extent. The authors hope for improvements at this point and better support for future extension projects.

\section{Conclusion}

The project has proven that the creation of a well-defined extension of IFC in limited time frame is possible. The formalized processes of buildingSMART International help to deliver a high quality product, ensuring both its technical validity and its applicability in the target domain. 


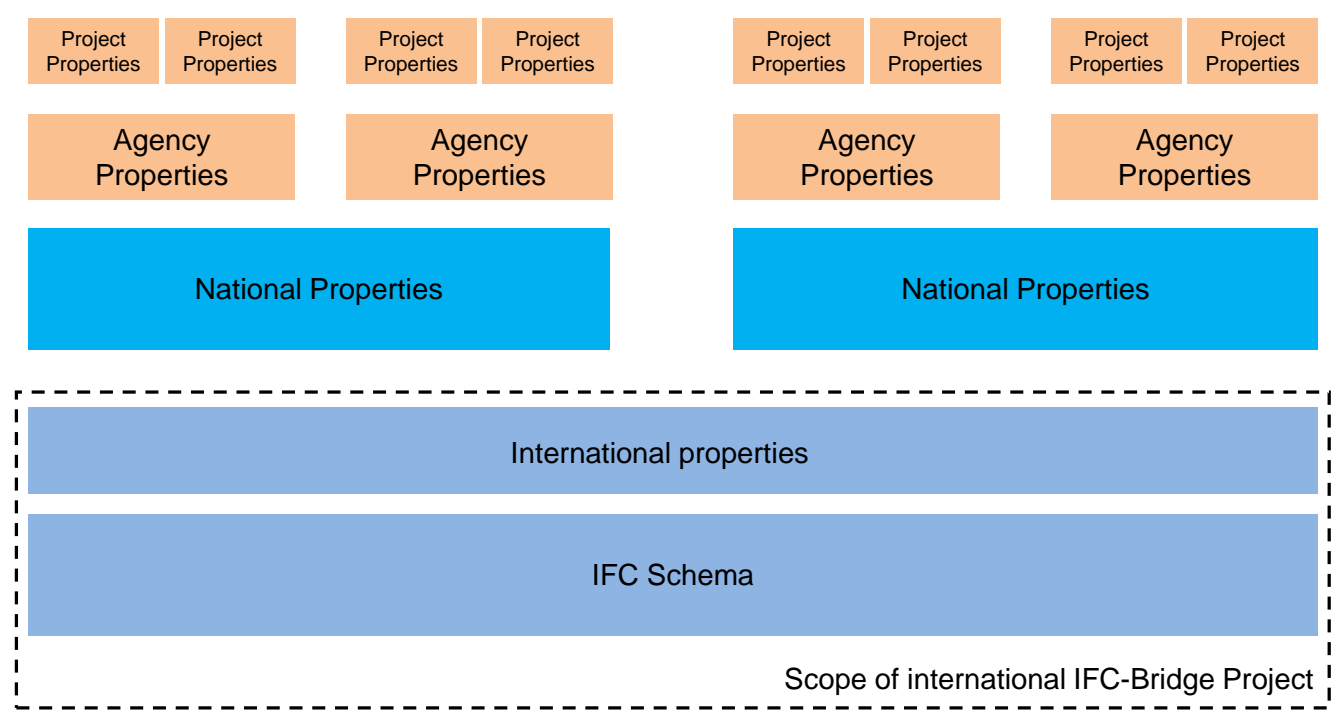

Figure 9: The extension mechanisms of IFC allow the definition of properties on different levels.

\section{Acknowledgements}

The IFC-Bridge project was funded by the German Ministry of Transport, the French research project MiND, the Finnish Transport Agency and the Swedish Transport Agency Trafikverket.

\section{References}

Amann, J., Schöttl, F., Singer, D., Kern, M., Widner, A., Geisler, P., Below, D., Hecht, H., Gupta, N., Mustafa, A., Markič, S. \& Borrmann, A. (2016), 'TUM Open Infra Platform 2017'.

URL: https://www.cms.bgu.tum.de/oip

Borrmann, A., Amann, J., Chipman, T., Hyvärinen, J., Liebich, T., Muhič, S., Mol, L., Plume, J. \& Scarponcini, P. (2017), 'IFC Infra Overall Architecture Project: Documentation and Guidelines', https://buildingsmart. org/wp-content/uploads/2017/07/08_bSI_ OverallArchitecure_Guidelines_final.pdf. Accessed: 2018-01-12.

Borrmann, A., Beetz, J., Koch, C., Liebich, T. \& Muhic, S. (2018), Industry foundation classes: A standardized data model for the vendor-neutral exchange of digital building models, in A. Borrmann, M. König, C. Koch \& J. Beetz, eds, 'Building Information Modeling', Springer.

buildingSMART International (2015), bSI Standards Process.

URL: https://www.buildingsmart.org/standards/standardsprocess/
Castaing, C., Borrmann, A., Benning, P., Dumoulin, C., Chipman, T., Hyvaerinen, J., Liebich, T., Markic, S., Mol, L., Muhic, S., Moon, H., Myllymaki, H., Suo, N., Song, S., Shanding, Ai an Siming, L., Yi, Z., Yabuki, N. \& Zhao, F. (2018), IfcBridge requirements analysis report, Technical report, buildingSMART International.

Hüthwohl, P., Brilakis, I., Borrmann, A. \& Sacks, R. (2018), 'Integrating RC Bridge Defect Information into BIM Models', Journal of Computing in Civil Engineering 32(3), 04018013.

Ji, Y., Borrmann, A., Beetz, J. \& Obergrießer, M. (2013), 'Exchange of Parametric bridge Models using a Neutral Data Format', Journal of Computing in Civil Engineering ASCE 27(6), 593-606.

URL: doi: $10.1061 /(A S C E) C P .1943-5487.0000286$

Laakso, M. \& Kiviniemi, A. (2012), 'The IFC standard: A review of History, development, and standardization, Information Technology', 17(9), 134-161.

Liebich, T., Amann, J., Borrmann, A., Chipman, T., Hyvärinen, J., Muhič, S., Mol, L., Plume, J. \& Scarponcini, P. (2017), 'IFC Alignment 1.1 Project, IFC Schema Extension Proposal'.

Sacks, R., Kedar, A., Borrmann, A., Ma, L., Brilakis, I., Hüthwohl, P., Daum, S., Kattel, U., Yosef, R., Liebich, T., Barutcu, B. E. \& Muhic, S. (2018), 'Seebridge as next generation bridge inspection: Overview, information delivery manual and model view definition', $A u$ tomation in Construction 90, 134-145. 